\title{
Visiones abarcadoras del pasado en la Mesopotamia antigua: el problemático equilibrio entre lo mítico y lo histórico*
}

(4) Andrea Seri

Universidad Nacional de Córdoba, Argentina

Fecha de recepción: 2 de junio de 2020. Fecha de aceptación: 15 de junio de 2020.

\begin{abstract}
Resumen
Documentos provenientes de tradiciones diversas muestran que en la Mesopotamia antigua el pasado se representaba de varias maneras. Entre esos textos se encuentran listas reales, narrativas con fuertes componentes míticos, composiciones con rasgos literarios evidentes, presagios que vinculan resultados positivos o nefastos con reyes icónicos, inscripciones reales que cuentan las hazañas de los gobernantes y, más tarde, aparecen los anales asirios que registran campañas reales. Surgen, también, las crónicas de contenido ecléctico. Los agentes de cambio son dioses que premian o castigan, soberanos implacables o el simple devenir. La veracidad de hechos y personajes del pasado, sean mitológicos, fantásticos o reales, no parece haber despertado demasiadas suspicacias. En este trabajo se analiza la manera en la que la Lista Real Sumeria y la Babiloniaca de Beroso entrelazan hechos y personajes ficticios y reales para ofrecer visiones abarcadoras del pasado en un juego de equilibro entre lo mítico y lo histórico.
\end{abstract}

Palabras clave: historia, historiografía, Lista Real Sumeria, Babiloniaca, Beroso

\footnotetext{
* Texto revisado de una conferencia presentada en el marco de las I Jornadas de Investigación del Instituto de Historia Antigua Oriental, Ciudad Autónoma de Buenos Aires, 14 de mayo de 2019.
} 


\title{
Comprehensive Views of the Past in Ancient Mesopotamia: The Problematic Balance between the Mythical and the Historical
}

\begin{abstract}
Documents originating from diverse traditions show that in ancient Mesopotamia the past was conveyed in various ways. Among those texts are royal lists, narratives with strong mythical components, stories with evident literary features, omens that link positive or disastrous results with iconic kings, royal inscriptions recounting the exploits of kings and, later, the Assyrian annals that register royal campaigns. There are also chronicles of eclectic content. The agents of change are punishing or rewarding gods, implacable sovereigns or simply change itself. The truthfulness of events and characters from the past, whether mythological, fantastic or real, does not seem to have raised too much suspicion. In this work I analyze the way in which the Sumerian King List and Berossus's Babyloniaca intertwine fictitious and real events and characters to offer comprehensive views of the past in a game of balance between the mythical and the historical.
\end{abstract}

Keywords: history, historiography, Sumerian King List, Babyloniaca, Berossus

\section{El contexto y la idea de historia en el Cercano Oriente antiguo}

El desciframiento de la escritura cuneiforme a mediados del siglo XIX permitió que se pudieran volver a leer documentos escritos en lenguas completamente inaccesibles desde el siglo II de nuestra era (ver Houston, Baines y Cooper, 2003: 456). Filólogos decimonónicos emprendieron entonces el desafío de escribir la historia en base a fuentes primarias directas y el de comparar y contrastar esas evidencias con la información disponible en textos bíblicos y greco-latinos. Con bastante asiduidad desde el siglo XX, algunos expertos en las lenguas pretéritas del Cercano Oriente han buscado evidencias para probar o refutar la existencia de una idea de historia e historiografía en sociedades antiguas como aquellas que habitaban los territorios de Mesopotamia, Persia, Anatolia y el Levante. Esa búsqueda ha dado como resultado una variedad de trabajos con diferentes grados de originalidad y desafío. Se partía, por lo general, de ideas algo clásicas y bastante difusas de qué era y cómo debía escribirse la historia. Había que encarar, además, el problema de cómo clasificar textos en sociedades que no utilizaban las categorías y las convenciones de los géneros textuales tradicionales. Y era imperioso destilar lo mítico de lo histórico.

Algunas de esas dificultades habían sido percibidas poco tiempo después de que Heródoto completara sus novedosas historíai y, con ellas, diera inicio a la historia y a la historiografía. Sería ese el comienzo de los persistentes debates sobre qué es y cómo se escribe la historia. Como iniciador de nuevas formas de escribir sobre el pasado, Heródoto recibió el título honorífico de "padre de la Historia", pero fue también merecedor de críticas mordaces de sucesivos practicantes de su oficio. ${ }^{1}$ Para Tucídides, por ejemplo, los métodos de Heródoto no 
eran confiables. Y Aristóteles lo llamó cuentacuentos. Incluso Cicerón, quien le adjudicó la paternidad de la Historia, pensaba que el trabajo de Heródoto abundaba en leyendas; y así lo expresó en su libro sobre las Leyes al afirmar que "hay innumerables fábulas tanto en Heródoto, el padre de la historia, como en Teopompo" (De Legibus 1.5). Para Cicerón, el objetivo de la Historia era la verdad. Con los años, la incomodidad que causaba la figura de Heródoto, parte historiador y parte relator de muthoi, hizo que se lo colocara en el "umbral de la historia" porque su obra desdibuja categorías y elude las leyes de los géneros (Hartog, 1988: 379). El interés por explicar el lugar de Heródoto en la historia de la historiografía permite rastrear algunas inquietudes surgidas desde los orígenes de la disciplina y que giran en torno a fuentes y método, verdad y mentira, historia y literatura. ${ }^{2}$

Presentar esos conceptos en una lista simplificada subestima la complejidad de problemas que han impregnado el horizonte intelectual de Occidente durante varios siglos. Lejos de desvanecerse en la Antigüedad, esas tempranas discusiones sobre el estatus de Heródoto y sobre la escritura de la historia se han mantenido vigentes en la literatura latina hasta el Medioevo y se potenciaron durante el Renacimiento con las ediciones griegas de las Historias de Aldus Manutius (1502) y de Henri Estienne (1570) y con las traducciones al latín de Guarino Veronese (1415, libro 1), de Mattia Palmieri (c. 1450) y de Lorenzo Valla (1455) y, más tarde, con las traducciones a lenguas vernáculas, como la de Pierre Saliat al francés (1552-1556) y la de Matteo Maria Boiardo al italiano (1533-1565). ${ }^{3}$ Desde el siglo VII, con las Etimologiae de Isidoro de Sevilla, hasta el siglo XV no faltaron sugerencias para reemplazar a Heródoto como el primer historiador: entre los candidatos propuestos figuraron Moisés, Dares de Frigia y Dictis de Creta. ${ }^{4}$ Vinieron luego las reivindicaciones a favor de la disputada credibilidad de Heródoto por parte de Enrico Stefano en su Apologia pro Herodoto (1566) y, casi dos siglos más tarde, la Défense d'Hérodote del abad Genoiz (1756). Esas obras evidencian una centenaria coexistencia de críticos y defensores de Heródoto y, en ese devenir, uno de los cuestionamientos más persistentes era el de la veracidad.

Puede decirse que, desde Heródoto y Tucídides hasta entrado el siglo XIX, las principales tendencias en la escritura de la historia consistían en variaciones de historias políticas y militares que contaban entre sus antepasados distantes

y IV a.C., respectivamente (Marincola, 2016: 104). Y no puede dejar de mencionarse, por supuesto, a Plutarco y su De Herodoti malignitate, en el siglo I d.C.

2 Las diferencias entre el oficio del historiador y del poeta aparecen ya mencionadas en La poética de Aristóteles (9.1-10). Más tarde, en su Quomodo sit historia conscribenda, Luciano se refiere al método y a la relación entre historia y panegírico, historia y poesía, e historia, mentira y verdad.

3 Para un recorrido pionero por ciertos detractores y admiradores de Heródoto, ver Momigliano (1958). Para las recepciones de Heródoto, ver las contribuciones en el volumen editado por Priestley y Zali (2016).

4 Momigliano (1957: 75) los llama "pretendenti alla paternità della storia". Por su parte, Foley (2016: 214) ha observado que, en el siglo XV, Valla incluye a Moisés, Dares y Dictis en su discusión sobre historia antigua en el proemio de su Gesta Ferdinandi Regis. 
a aquellos viejos relatos sobre las guerras persas y la guerra del Peloponeso. Para mediados del siglo XIX, muchos historiadores consideraban a Tucídides el inventor de la historiografía científica moderna, porque su rigurosidad y su método presuntamente coincidían con los intereses de los historiadores de la época (Morley, 2016: 149). En el prefacio a su Geschichten der romanischen und germanischen Völker von 1494 bis 1514, fechado en octubre de 1824, Leopold von Ranke había escrito su legendaria frase wie es eigentlich gewesen, "como fue en realidad", remarcando, de manera indirecta, la importancia de la verdad en la escritura de la historia (von Ranke, 1885: vii). Unos pocos años después, G. F. W. Hegel, en una de sus conferencias sobre la Historia Mundial, se hizo eco de ese lema. ${ }^{5}$

El siglo XX fue el escenario donde surgieron propuestas que significaron cambios drásticos en las prácticas historiográficas. El proyecto de Ranke y el predominio de la historia política y militar fueron cuestionados por los propulsores de la historia económica, social y cultural. A modo de ejemplo, se puede mencionar el artículo de François Simiand de 1903 donde critica a "los tres ídolos de la tribu de historiadores: el ídolo de la política, el ídolo de lo individual y el ídolo de la cronología" (Burke, 1993: 11). En 1929 Marc Bloch y Lucien Febvre crearon la revista Annales d'histoire économique et sociale, que marcó época. Aparecieron luego la new economic history en Estados Unidos y la histoire sérielle en Francia. Se publicaron análisis macro históricos como los Studies in the Development of Capitalism de Maurice Dobb en 1946 y La Méditerranée de Fernand Braudel en 1949 (ver Dobb, 1946; Braudel, 1949). Surgió la microhistoria (por ejemplo, Ginzburg, 1976). En 1979 Lawrence Stone señalaba una tendencia a cuestionar y rechazar la idea de que es posible realizar una explicación científica del cambio en el pasado (Stone, 1979). De ese modo, las premisas para una "historia total" surgidas en la primera mitad del siglo $\mathrm{XX}$, allanaron el camino para la fragmentación de la disciplina en una multiplicidad de áreas con diferentes propuestas teóricas y metodológicas: historia desde abajo, estudios subalternos, historia de las mujeres, microhistoria, historia del acontecimiento, historia del cuerpo e historia del pensamiento político son sólo algunas de las propuestas (ver Burke, 1995). Este recorrido parcial y breve muestra cómo han ido cambiando las maneras de escribir la historia y da indicios de las complicadas transiciones que han ido transformando verdades absolutas en verdades relativas. ${ }^{6}$

Desde las indagaciones y las fábulas de Heródoto, pasando por el wie es eigentlich gewesen de Ranke, hasta la metahistoria de Hayden White y sus detractores, las tensiones entre lo mítico y lo histórico, lo legendario y lo verídico, lo ideológico y lo objetivo, la historia y la ficción han permeado las discusiones sobre la manera de representar el pasado y de escribir la historia. En retrospectiva,

5 Así aparece en el segundo borrador de 1830 de su conferencia sobre "La historia filosófica del mundo" (Hegel, 1998: 26).

6 En el siglo XX fueron difuminándose las esperanzas de ofrecer las perspectivas objetivas del pasado a las que aspiraban historiadores como Michelet, Ranke y Burkhardt, así como fue perdiendo fuerza la propuesta de K. Marx que buscaba transformar el estudio de la historia en ciencia. Ver White (1973: 39-40). 
después de siglos de historiografía occidental, a Heródoto se lo colocó en el umbral de la historia, un viejo ídolo al que se lo saluda de manera ritual. ${ }^{7}$ Moisés, Dares y Dictis quedaban descartados de la disputa por la paternidad de la historia. Pero al igual que Moisés, Heródoto representaba un punto de intersección entre Oriente y Occidente; sobre todo, de aquel Oriente que había descripto en los primeros libros de sus Historias. Se ha debatido acerca de las fuentes a partir de las cuales Heródoto compuso sus narrativas orientales. Cuando en el siglo XIX se descifraron el sistema de escritura jeroglífico primero y, luego, el cuneiforme, comenzaron a salir a la luz fuentes autóctonas desconocidas hasta ese entonces. Los interrogantes eran varios y diversos. ¿Se escribía historia antes de Heródoto? ¿Había una idea de la historia en la Mesopotamia antigua? ¿Había textos históricos? ¿Cómo clasificar las fuentes narrativas cuneiformes? ¿Cómo filtrar lo mítico de lo histórico? En sentido estricto, ninguna de esas preguntas ha podido ser respondida de manera concluyente, quizás porque existen puntos de partida e interpretaciones discordantes.

Esas inquietudes eran previsibles, porque, a decir de Arnaldo Momigliano, "la gente que fue a excavar a Egipto y Mesopotamia tenía a Heródoto como principal guía" 8 y porque conocía, al menos en parte, el resultado de siglos de discusiones historiográficas previas. Analizar textos que eludían los parámetros clásicos y bíblicos causaba cierta incomodidad, mientras continuaba sobrevolando el dilema de lo mítico y lo histórico. Resultaba difícil no quedar atrapado en ese tapiz de tradiciones entretejidas a partir de Heródoto. En 1956, el sumerólogo Samuel Kramer publicó un libro de divulgación intitulado History Begins in Sumer (La historia empieza en Sumer). A lo largo de veintisiete capítulos explica veintisiete cosas que, según él, ocurrieron por primera vez en Sumer. El capítulo sexto está dedicado al "primer historiógrafo" que escribió, precisamente, sobre una guerra. En la primera oración, Kramer advierte "Hay que reconocer que Sumer no ha producido ningún historiador digno de este nombre" (Kramer, 1978 [1956]: 85) y unas páginas más adelante agrega "resulta sorprendente que no se pueda encontrar nada en Sumer que se asemeje al tipo de obras históricas tan extendidas entre hebreos y griegos" (Kramer, 1978 [1956]: 87). Esas afirmaciones muestran el espíritu de época en su disciplina. Casi cinco décadas después, en un artículo sobre la invención de la historia, François Hartog daba por sentado que la historia y su escritura no habían comenzado en Grecia sino en Oriente. ${ }^{9}$

De este recorrido se desprende que es insostenible pensar que ha habido sólo una idea de historia o, en términos más amplios, una única manera de

7 Según Hartog (1988: 379), "If he is installed out there on the threshold of history, an old blackened idol to be ritually saluted, the very mention of his name may have apotropaic effects: it assures the addressee that my own text is not telling lies."

8 "The people who went to excavate Egypt and Mesopotamia had primarily Herodotus as their guide" (Momigliano, 1958: 13). Se deberían agregar, además, la Biblia y otros autores clásicos.

9 Comenta: "It is well-known that history and its writing did not begin in Greece; rather it began further to the East and earlier" (Hartog, 2002: 19); se refería, específicamente, a Egipto y Mesopotamia. 
transmitir el pasado en el transcurso de tres milenios de escritura cuneiforme. Pensar que esas ideas se pueden reconstruir de forma unilineal es ilusorio. Por cierto, documentos provenientes de tradiciones diversas muestran que en la Mesopotamia el pasado se capturaba utilizando diferentes estrategias. Entre los textos más representativos se encuentran inscripciones votivas, listas reales, relatos con fuertes componentes míticos, narraciones con rasgos literarios evidentes, presagios que vinculan resultados positivos o nefastos con reyes icónicos, inscripciones reales donde se enfatizan los logros de monarcas virtuosos y aguerridos, nombres de años que seleccionan y resumen acontecimientos encomiables. Más tarde, a partir de la segunda mitad del segundo milenio, aparecen los anales asirios que, con minuciosidad, registran campañas reales colmadas de victoriosas masacres. Surgen también las crónicas de contenido ecléctico. Estos textos conllevan, de manera más o menos aparente, una agenda que no siempre es la misma. Los agentes del cambio son dioses que premian o castigan, soberanos implacables o el simple devenir. Tal como en Heródoto, y en autores posteriores, ${ }^{10}$ la veracidad de hechos y personajes del pasado, hayan sido mitológicos, fantásticos, divinos o reales, no siempre parece haber despertado suspicacias. ${ }^{11}$ En vista de esa variedad de enfoques, en este trabajo propongo analizar cómo se escribió sobre el pasado en dos textos de la Mesopotamia antigua: la Lista Real Sumeria y la Babiloniaca de Beroso, dos obras de veracidad cuestionada, donde "lo mítico se mezcla con lo histórico". ${ }^{2}$

\section{La Lista Real Sumeria y la Babiloniaca de Beroso}

De entre el corpus de textos autóctonos que dan cuenta del pasado en la Mesopotamia antigua, la Lista Real Sumeria y la Babiloniaca de Beroso coinciden en ofrecer visiones abarcadoras en un verdadero despliegue de la longue

10 Gabba (1981: 53-54) sostiene que hacia el final del Período Clásico y en el Período Helenístico los trabajos de historia retoman las fases míticas y legendarias de la prehistoria y la protohistoria griegas. Y agrega que quienes escribían sobre historiografía en los períodos Helenístico y Romano aceptaban la historia divina como narrativa de acontecimientos, ya que a la "historia verdadera" se le asignaban, además de las acciones humanas, las biografías de dioses y héroes junto con las de hombres famosos.

11 La convivencia de lo mítico, lo legendario y lo histórico se mantiene en obras del siglo XVII, como cuando en sus Discours sur l' histoire universelle, escritos en 1681, Bossuet (1844: 8) menciona en "les temps de l'histoire ancienne" a "Adam, ou la création"; "Noé, ou le déluge"; "la prise de Troie"; "Romulus, ou Rome bâtie" y "Charlemagne, ou l'établissement du nouvel empire". Ya en el siglo XIX, en el primer capítulo de la tercera edición de su Manuel d'histoire ancienne de l'Orient, Lenormant advierte que la Biblia "devrait toujours, en saine critique, être la base du récit de tout historien, car (...) elle contient la plus antique tradition sur les premiers jours de la race des hommes, la seule qui n'ait pas été défigurée par l'introduction des mythes fantastiques, dans lesquels une imagination déréglée s'est donné libre carrière" (Lenormant, 1869: 1).

12 Tal la expresión que utilizó Hegel (1942: 200) en su Filosofía de la Historia para referirse a la historia del Egipto antiguo. Sostiene: "The History of Egypt, as we have it, is full of the greatest contradictions. The Mythical is blended with the Historical, and the statements are as diverse as can be imagined". 
durée. Comienzan desde los orígenes hasta llegar al presente del compilador. En ese ejercicio de vincular lo contemporáneo con el arcaísmo más remoto no se escatiman milenios. Ambos documentos contienen, además, una sección dedicada al pasado mítico-legendario y otra referida a un pasado menos fantástico. Compuestos en contextos históricos muy diferentes - al menos unos dieciocho siglos separan a un texto del otro- los dos dependen de materiales cuneiformes y de tradiciones culturales para transmitir sus visiones de ciertos acontecimientos del pasado. También comparten el hecho de contar con historias de transmisión textual complejas. En el caso de la Babiloniaca, existe el problema adicional de que se preserva sólo parte del contenido, rearmado en base a los pasajes citados por autores posteriores, quienes, a su vez, no tuvieron acceso directo al texto de Beroso, sino que dependieron de extractos y citas de otros autores.

\subsection{La Lista Real Sumeria}

Escrita en sumerio, en la Mesopotamia antigua se la conocía por el íncipit, nam-lugal an-ta $\mathrm{ed}_{3}$ - $\mathrm{de}_{3}$-a-ba, "después de que la realeza descendiera del cielo". Existen varias versiones de la Lista Real Sumeria, provenientes de diferentes sitios arqueológicos que, en su mayoría, son ejemplares preservados en estado fragmentario. ${ }^{13}$ Las variaciones entre esas copias se evidencian en detalles tales como el orden de sucesión de las dinastías, las fórmulas para indicar cambios dinásticos, la secuencia de reyes, la cantidad de años de reinado y las características de algunas de las anotaciones. Pero, además, los manuscritos difieren en cuanto al punto de partida y al punto de llegada de los acontecimientos narrados. El primer fragmento importante fue publicado en 1906. En 1923 apareció la edición del prisma Weld-Blundell, notorio por el buen estado de preservación y por incluir la sección antediluviana de reyes. ${ }^{14}$ La primera edición exhaustiva, que incluía todos los fragmentos conocidos en ese entonces y ofrecía un texto compuesto, apareció en 1939 (Jacobsen, 1973). Hasta principios de este siglo, el material disponible parecía indicar que la Lista Real Sumeria había sido creada durante el período Paleobabilónico temprano, más precisamente, bajo la Primera Dinastía de Isin (ca. 2017-1794 a.C.). Sin embargo, en 2003 se dio a conocer una copia, de procedencia incierta, que data de la III Dinastía de Ur (ca. 2100-2000 a.C.) (Steinkeller, 2003). Esta tablilla ofrece sólo la versión posdiluviana, cuando la realeza baja del cielo, por primera vez, a la ciudad de Kiš. En esta recensión, al igual que en algunos otros manuscritos paleobabilónicos de Nippur, se usó una expresión acadia —mannu šarrum mannu lā šarrum, “¿Quién era rey? ¿Quién no era rey?” (rev. iv:26’-27’) ${ }^{15}$ — para señalar el vacío de poder imperante después de la caída de la Dinastía de Agade.

La aparición del manuscrito proveniente de la III Dinastía de Ur corrió hacia atrás la fecha del ejemplar más antiguo e hizo revisar las hipótesis sobre la época

13 De los manuscritos cuya procedencia es cierta, varios fueron descubiertos en Nippur, y otros provienen de Susa, Kish, Larsa (Jacobsen, 1973: 5-13), Isin, Sippar, Tell Harmal, Tutub y Tell Leilān (Vincente, 1995: 237-238).

14 Hilprecht (1906). El prisma Weld-Blundell fue publicado por Langdon (1923).

15 En acadio también en los manuscritos L1+N1 y P3+BT14. 
de composición del documento. Ahora se sabe que, si bien hay varias versiones paleobabilónicas, la Lista Real Sumeria ya existía durante la segunda mitad del reinado de Šulgi y que, en realidad, puede haber sido compuesta durante la dinastía de Agade. ${ }^{16}$ Cualquiera haya sido el período de origen, lo cierto es que lo que llamamos "la" Lista Real Sumeria son en realidad varias listas con una larga y compleja historia redaccional. ${ }^{17}$ Se trata de un trabajo anónimo, como en la mayoría de las obras cuneiformes, ${ }^{18}$ en el que escribas diligentes adaptaban el contenido, mutatis mutandi, según las conveniencias de la época. Esto explica, en parte, la variabilidad del texto. A pesar de las distintas interpretaciones sobre aspectos específicos, en general los estudiosos concuerdan en que el documento buscaba transmitir la idea de que, en la Mesopotamia, desde tiempos inmemoriales, una dinastía a la vez ostentaba el dominio sobre todo el territorio de Sumer y Acad. El poder rotaba, con cierta regularidad, por unas cuantas ciudades y sus respectivas dinastías.

\subsection{La Babiloniaca de Beroso}

La Babiloniaca o Historia de Babilonia escrita por Beroso, un sacerdote del templo Esaĝil en Babilonia, data del Período Helenístico temprano. ${ }^{19}$ Todavía se desconocen muchos detalles sobre la trayectoria de Beroso y hay interpretaciones divergentes sobre ciertos aspectos de su biografía. ${ }^{20} \mathrm{Su}$ obra fue escrita en griego para un público griego. Se asume que fue dedicada a Antíoco I cuando actuaba como corregente de su padre, Seleuco I (desde el 295-294 al 281 a.C.), $y$, por consiguiente, debe haber sido escrita entre esos años o durante los de su propio reinado (281-261 a.C.). Para ese entonces, Heródoto ya había escrito sus historíai y, desde el 539 a.C., ningún rey nativo había vuelto a gobernar los territorios que habían pertenecido al imperio babilónico. El mundo de

16 Ver Wilcke (2001: 108-115). Steinkeller (2003: 282) argumenta que el texto podría haber sido compuesto durante la dinastía de Agade porque Sargón y sus descendientes tenían un claro interés en promover la idea de que Kiš había sido el asiento de la realeza desde tiempos inmemoriales hasta la dinastía de Agade. Más recientemente Marchesi (2010: 233) sostiene que el manuscrito de Ur III da indicios para pensar en una versión del período sargónico escrita en lengua acadia.

17 En palabras de Michalowski (1983: 243), "Given the state of our knowledge we can only assume that there are as many King Lists as there are manuscripts".

18 Para el problema de la autoría en la literatura cuneiforme, ver Foster (1991).

19 Beroso es la versión griega de un nombre cuya forma acadia original es incierta. Entre las posibilidades sugeridas aparecen: Bēl-ușuršu, "¡Oh Bēl, protégelo!" (ver Beaulieu, 2007: 119); Bēl-rề ûšunu, "Bēl es su pastor", con el sufijo pronominal en masculino plural, (e.g., Van der Spek, 2000: 439; De Breucker, 2011: 635); y Bēl-rê’ûšu, "Bēl es su pastor", con el sufijo pronominal en masculino singular (Lehmann-Haupt, 1938: 2a; Komoróczy, 1973: 125; Verbrugghe y Wickersham, 2000: 13). En la Babilonia de los períodos Aqueménida Tardío y Helenístico, el nombre más común parece haber sido Bēl-

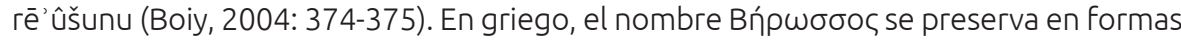
escritas con una o dos sigmas y con diferentes acentos (ver De Breucker, 2013: 15 n. 1).

20 En los últimos años ha habido un creciente interés en la obra de Beroso, como puede apreciarse a partir de la publicación de un volumen que reúne el trabajo de especialistas (Haubold et al., 2013) y otro dedicado a Beroso y Manetón (Dillery, 2015). 
la Babiloniaca de Beroso tenía muy poco que ver con la Mesopotamia de la Lista Real Sumeria, pero en ambos textos el peso de la tradición cuneiforme es determinante. La obra de Beroso se conoce por los fragmentos preservados en los epítomes de escritores paganos, judíos y cristianos, entre los que se destacan Josefo (37/8-100 d.C.), Eusebio (ca. 260-340 d.C.) y Sincelo (ca. 810 d.C.). ${ }^{21}$ Las tres principales fuentes tempranas para la transmisión de Beroso fueron los extractos de Alejandro Polihistor (ca. 110-40 a.C) y Juba de Mauritania (50 a.C.-23 d.C.), que no han sobrevivido hasta el presente, y el Glosario de Oxirinco (ca. siglo I a.C. y II d.C.). ${ }^{22}$ Por lo general, los pasajes preservados coinciden con los intereses de los intelectuales que consultaban la Babiloniaca. Josefo, por ejemplo, intentaba demostrar que no había pueblo más antiguo que el judío y Eusebio buscaba armar una cronología que incluyera al mundo pagano y al judeo-cristiano; ambos querían probar que la cronología bíblica era correcta. ${ }^{23}$ Y Sincelo, después de incluir en su Ecloga Chronographica la explicación del diluvio de Beroso, le aconseja al lector remitirse al Génesis bíblico para conocer lo que realmente sucedió. ${ }^{24}$

La Babiloniaca consistía en tres libros; sobreviven algunos pasajes de cada uno de ellos. En el Libro I, Beroso se presenta, da cuenta de sus fuentes, describe la geografía, la fauna, la flora y el carácter multiétnico de la población. Pasa luego a aquellos tiempos inmemoriales cuando Oannes, especie de hombre-pez, apareció del mar para enseñarles a los hombres las artes de la civilización, es decir, la escritura, las matemáticas y cómo construir ciudades y templos, dictar leyes, establecer límites para dividir la tierra, cómo sembrar y cosechar. Al final del día Oannes volvió al mar y, con el tiempo, aparecieron otros seres similares que completaron sus enseñanzas. Después, Beroso refiere lo que Oannes había escrito para explicarles a los hombres sobre la creación y el gobierno del mundo. Narra, entonces, cómo Bēl (Marduk) derrotó a Omorka (Ti'āmat) y creó el universo y dio vida a los hombres. El Libro II presenta a los reyes babilónicos, partiendo de los monarcas antediluvianos, pasando por el Gran Diluvio, para referirse luego a los reyes posdiluvianos, posiblemente, hasta Nabonasar (747734 a.C.) (Schnabel, 1923: 22-23; Verbrugghe y Wickersham, 2000: 17; Lang, 2013: 48). Por último, el Libro III cubre la historia de Babilonia desde Nabonasar hasta Alejandro Magno (330-323 a.C.) (De Breucker, 2013: 23), con las lagunas previsibles, que pueden atribuirse a las preferencias de los transmisores de la obra. ${ }^{25}$ Se ha especulado sobre si, con su Babiloniaca, Beroso pretendía congra-

21 Ver De Breucker (2013); Verbrugghe y Wickersham (2000: 27-31); Burstein (1978: 6-11) y Schnabel (1923: 94-171).

22 Schironi (2013: 235 n. 1) analiza esos textos y proporciona una lista de las fuentes que contienen fragmentos de Beroso en orden cronológico.

23 Así lo señalan Verbrugghe y Wickersham (2000: 33).

24 Sincelo advierte: "It is possible for those wishing to understand correctly what really happened to refer to the holy writings of Genesis (6.5-9.17) to see how much they differed from the above account of the Chaldeans, full of unbelievable stories" (Verbrugghe y Wickersham, 2000: 51).

25 Para un análisis reciente de cada uno de los libros, ver los artículos de Haubold (2013), Lang (2013) y Lanfranchi (2013). 
ciarse con los gobernantes seléucidas y brindarles una legitimación ideológica anclada en el antiquísimo pasado mesopotámico. ${ }^{26}$ Pero, además, no habría que desestimar la posibilidad de que entre sus objetivos estuviera también el de preservar la información contenida en un sistema de escritura y en lenguas a los que les iba quedando cada vez menos aliento de vida.

\section{La larga duración en la Lista Real Sumeria y en la Babiloniaca ${ }^{27}$}

En la Lista Real Sumeria el tiempo comienza a medirse a partir del momento en que la institución de la realeza baja por primera vez del cielo a la ciudad de Eridu. La lista consiste en la repetición bastante sistemática y previsible de una serie de enunciados básicos. De manera abreviada, en la edición compuesta la fórmula consiste en: 1) nombrar la ciudad que es asiento de la realeza, 2) mencionar el nombre del rey, 3 ) registrar la cantidad de años que gobierna (los pasos 2 y 3 se repiten para cada uno de los reyes que ejercen el poder), 4) computar el total de reyes que gobernaron sucesivamente en esa ciudad, 5) proporcionar la cantidad de años en que la realeza permaneció en esa ciudad, 6) documentar el traspaso de la realeza a otra ciudad y, a partir de allí, se repite el proceso, comenzando con el paso 1 hasta llegar al 6. El cambio del asiento de la realeza de una ciudad a otra ocurre en 25 oportunidades. ${ }^{28}$ Esa enumeración sistemática se ve interrumpida dos veces: primero por el Diluvio y más tarde por la anarquía.

El Diluvio opera como una cesura de alcance universal luego de la cual se reinicia el ciclo, con el segundo descenso celestial de la realeza, esta vez, a la ciudad de Kiš. El efecto de circularidad se logra mediante la repetición del íncipit, nam-lugal an-ta-ed ${ }_{3}-\mathrm{de}_{3}$-a-ba, "después de que la realeza descendiera del cielo" (ln. 41). ${ }^{29}$ En tanto la anarquía se presenta como un interludio político

26 Dillery (2015: xiv-xix) plantea las posturas opuestas de autores como Kuhrt (1987) y Green (1990) bajo el sugestivo subtítulo "Nationalism and Colonialism, Collaboration or Resistance?".

27 Utilizo aquí la versión de la Lista Real Sumeria que contiene la selección de reyes antediluvianos en el texto compuesto editado en el Electronic Text Corpus of Sumerian Literature (ETCSL) de la Universidad de Oxford (etcsl.orinst.ox.ac.uk/section2/c211.htm) y la edición de Beroso de Verbrugghe y Wickersham (2000). Tanto la versión compuesta de la Lista Real Sumeria — que combina varios manuscritos para llenar lagunas-como las ediciones modernas de la Babiloniaca - que rearman la narración de Beroso a partir de citas posteriores - son textos artificiales que no existían en la antigüedad de la manera que han sido editados en la actualidad. En ese sentido, son constructos recientes que podrían conducir a interpretaciones sesgadas.

28 En orden de aparición según la edición del ETCSL: 1. Eridu, 2. Bad-Tibira, 3. Larag, 4. Sippar, 5. Šuruppag, 6. Kiš, 7. Eana/Uruk, 8. Ur, 9. Awan, 10. Kiš, 11. Hamazi, 12. Uruk, 13. Ur, 14. Adab, 15. Mari, 16. Kiš, 17. Akšak, 18. Kiš, 19. Uruk, 20. Agade, 21. Uruk, 22. el país de los Guti, 23. Uruk, 24. Ur y 25. Isin.

29 Cabe señalar, sin embargo, que la adición del período antediluviano en posteriores recensiones hizo que el íncipit de la versión que comenzaba en época posdiluviana 
después del reinado de Šar-kali-šarri, que marca el fin de la dinastía iniciada por su bisabuelo Sargón de Agade. En este caso, la idea de que por primera vez desde tiempos muy remotos no hay un claro y único líder político se expresa por medio de las preguntas “¿quién era rey?, ¿quién era no rey?". Desde allí en adelante, la sucesión de ciudades y reyes continúa sin mayores sobresaltos. Siendo flexibles con los cómputos cronológicos de los antiguos escribas variables debido a posibles errores y corrupciones de las transmisiones-, se obtienen los siguientes valores numéricos: desde que la realeza bajó del cielo por primera vez hasta el diluvio, pasaron 241.200 años; y desde que la realeza volvió a descender después del diluvio, esta vez a la ciudad de Kiš, hasta el último rey de toda la lista transcurrieron 28.876 años. ${ }^{30}$ Eso da un gran total de 270.076 años desde el primer año en que el rey Alulim de Eridu comenzó a gobernar hasta el final del reinado de Sîn-māgir de Isin. Según la cronología moderna, Sîn-māgir ejerció el poder hasta el 1817 a.C.

El período del que se ocupa Beroso en sus tres libros es más extenso que el de la Lista Real Sumeria. Comienza con la creación del mundo hasta llegar a la dominación griega. Beroso parece haber precisado que en Babilonia se habían preservado numerosos documentos que cubrían más de 150.000 años. ${ }^{31}$ Según los comentarios de Eusebio, en el libro II Beroso proporciona un listado de reyes donde se enumera a un rey después de otro, en orden cronológico y mencionando, rara vez, alguna que otra hazaña sin mayores detalles. ${ }^{32}$ Ese formato de presentación es bastante similar al de la Lista Real Sumeria. Al igual que en la Lista Real, Beroso incluye una nómina de reyes de antes y después del Diluvio. Pero, a diferencia de la Lista Real, en la Babiloniaca se explica la aparición de Oannes y de varios otros hombres-pez que lo sucedieron y se los ubica temporalmente en los reinados de determinados reyes antediluvianos. Así, por ejemplo, Oannes apareció durante el reinado de Ammenon. En el de Daonos llegaron otros cuatro monstruos y, por último, durante el de Euedorankhos se presentó el hombre-pez Odakon. ${ }^{33}$

Aunque la Babiloniaca no haga referencia al descenso celestial de la realeza, el registro del primer rey y de la cantidad de años que gobernó permite anclar temporalmente la antigüedad aproximada del primer soberano. Según Beroso, Oannes se apersona durante el reinado del cuarto monarca antediluviano. Si la mención que se hace en el Libro I al "primer año" se refiere al primer año de gobierno de Ammenon, eso ubicaría la aparición del primer hombre-pez unos

(como es el caso del manuscrito de Ur III) quedara pospuesto. Una estrategia similar se observa en la versión en Babilónico Estándar de Gilgameš, donde el íncipit de la versión paleobabilónica, šūtur eli šarrī, queda relegado con la inclusión de una nueva introducción y, en este ejemplo, de un nuevo íncipit, ša nagba ìmuru.

30 Esas cifras aparecen en las líneas 28 y 430, respectivamente.

31 Libro I, Verbrugghe y Wickersham (2000: 43). Como lo ha señalado Burstein (1978: 13 ก. 3), esta cifra es problemática.

\section{Libro II, Verbrugghe y Wickersham (2000: 46-47).}

33 En 1962 se publicó un manuscrito cuneiforme en el que aparecen listados reyes antediluvianos y sabios apkallū. Ver van Dijk (1962). 
93.600 años después de que el primer rey, Aloros, comenzara a gobernar. ${ }^{34}$ Por inferencia, la civilización habría aparecido noventa y tres milenios y medio después del surgimiento de la realeza. Y desde la aparición del primer rey hasta la llegada del diluvio pasaron, según Beroso, 432.000 años (o 120 saroi). Es decir, unos 190.800 años más que los del período antediluviano de la Lista Real Sumeria. Y como en la Lista Real Sumeria, la cantidad de años de gobierno de los monarcas posdiluvianos, aunque difícil de calcular con total precisión, es significativamente más breve. Desde el primer rey después del Diluvio hasta el reinado de Darío I, habrían transcurrido unos 34.809 años.

La similitud de la lista de reyes antediluvianos de los dos textos ha sido señalada en reiteradas oportunidades. Aquí presento un cuadro comparativo para graficar las semejanzas y las diferencias, ${ }^{35}$

\begin{tabular}{|c|c|c|c|}
\hline \multicolumn{4}{|c|}{ Reyes antediluvianos } \\
\hline \multicolumn{2}{|c|}{ Lista Real Sumeria } & \multicolumn{2}{|c|}{ Babiloniaca ${ }^{36}$} \\
\hline 1. Alulim de Eridu & 28.800 años & 1. Aloros de Babilonia & 36.000 años \\
\hline 2. Alalĝar de Eridu & 36.000 años & 2. Alaparos de Babilonia & 10.800 años \\
\hline \multirow[t]{2}{*}{$\begin{array}{l}\text { 3. En-men-lu-ana } \\
\text { de Bad-tibira }\end{array}$} & 43.200 años & $\begin{array}{l}\text { 3. Amelon de } \\
\text { Pautibiblon }\end{array}$ & 46.800 años \\
\hline & & $\begin{array}{l}\text { 4. Ammenon de } \\
\text { Babilonia }\end{array}$ & 43.200 años \\
\hline $\begin{array}{l}\text { 4. En-men-gal-ana } \\
\text { de Bad-tibira }\end{array}$ & 28.800 años & $\begin{array}{l}\text { 5. Amegalaros } \\
\text { de Pautibiblon }\end{array}$ & 64.800 años \\
\hline $\begin{array}{l}\text { 5. Dumuzi de Bad- } \\
\text { tibira }\end{array}$ & 36.000 años & $\begin{array}{l}\text { 6. Daonos } \\
\text { de Pautibiblon }\end{array}$ & 36.000 años \\
\hline $\begin{array}{l}\text { 6. En-sipad-zid-ana } \\
\text { de Larak }\end{array}$ & 28.80o años & $\begin{array}{l}\text { 7. Euedorankhos } \\
\text { de Pautibiblon }\end{array}$ & 64.800 años \\
\hline $\begin{array}{l}\text { 7. En-men-dur-ana } \\
\text { de Sippar }\end{array}$ & 21.00o años & $\begin{array}{l}\text { 8. Amempsinos } \\
\text { de Larankhos }\end{array}$ & 36.0oo años \\
\hline \multirow{2}{*}{$\begin{array}{l}\text { 8. Ubār-Tutu de } \\
\text { Šuruppak }\end{array}$} & 18.600 años & 9. Otiartes de Larankhos & 28.800 años \\
\hline & & $\begin{array}{l}\text { 10. Xisouthros de } \\
\text { Larankhos }\end{array}$ & 64.800 años \\
\hline Total & 241.200 años & & 432.000 años \\
\hline
\end{tabular}

34 En el Libro I se dice: "In the very first year there appeared from the Red Sea (the Persian Gulf) (...) a frightening monster, named Oannes...". Y en el Libro II se afirma: "And after Amelon, Ammenon, the Chaldean reigned. During his reign, the Monster Oannes, the Annedotos, appeared from the Red Sea (the Persian Gulf)..." Verbrugghe y Wickersham (2000: 44, 489). Mi interpretación difiere de la presentada en la tabla B de Verbrugghe y Wickersham (2000: 71) en la que se equiparan los monstruos sabios de Beroso con los de Abideno y la lista de sabios W 20030, 7.

35 El cuadro es una versión modificada del que aparece en Verbrugghe y Wickersham (2000: 70).

36 Una lista similar a esta aparece en la traducción armenia y en la Ecloga Chronographica de Sincelo (Verbrugghe y Wickersham, 2000: 48-49). 
No es este el lugar de comparar exhaustivamente estos y otros textos que contienen información similar, ni el de discutir las fuentes de Beroso, para lo que ya existen estudios. ${ }^{37}$ Simplemente quiero señalar algunos puntos que pueden pasar desapercibidos a simple vista. Si bien es claro que Alulim y Aloros son el mismo rey, en algunas tradiciones del primer milenio Babilonia solía equipararse con la ciudad de Eridu, al punto de escribirse con el mismo logograma, nun. Eso explicaría que Beroso nombre a Babilonia en lugar de Eridu. La fusión de Sippar y Šuruppak en Larankhos es difícil de explicar y la homologación de Larak con Pautibiblon podría deberse a una corrupción del proceso de transmisión. En la Lista Real Sumeria el Diluvio ocurre cuando Ubār-Tutu ostentaba el poder en Šuruppak. Beroso, por su parte, ubica al diluvio durante el reinado de Ziusudra, un rey que no aparece en la Lista Real Sumeria, pero que se conoce en la tradición mesopotámica con los nombres de Ziusudra, Atra-ḩasīs y Uta-napištim. No es otro que el héroe del diluvio al que algunos textos lo presentan como hijo de Ubār-Tutu.

Tanto la Lista Real Sumeria como la Babiloniaca, otorgan un lugar central a la institución de la realeza y ambos textos comienzan a computar el tiempo a partir de los años de reinado del primer monarca. Esa larga duración — que comienza con el primer año de Alulim y llega al presente del escriba que adaptaba su versión de la Lista Real Sumeria y al presente de Beroso- buscaba anclar el pasado mesopotámico en tiempos tan distantes como prácticamente inconmensurables. Es una larga duración surgida de la concatenación de acontecimientos puntuales. La manera de expresar esa distante antigüedad disimulaba conflictos y rivalidades políticas y unificaba las tradiciones de Sumer y Acad y, más tarde, de Babilonia bajo el manto de la cultura cuneiforme. En el largo proceso de transmisión textual se filtraron varias inconsistencias. Los dos textos, a pesar de los dieciocho siglos que los separan, dan cuenta de un pasado ficticio que conllevaba un fin político similar, el de mostrar hegemonía y continuidad.

\section{Lo mítico y lo histórico}

En la Lista Real Sumeria abundan personajes mitológicos, literarios e históricos que comparten la característica de ser figuras de autoridad política y militar. Se los menciona de varias maneras: sin ningún tipo de calificativo, con indicación de profesión, con filiación paterna (o, en un caso, fraterna) o con una breve nota biográfica. En la mayoría de los casos al rey se lo alista sólo por el nombre. Unos nueve monarcas tienen alguna profesión como la de pastor (sipad), en los casos de Dumuzi de Bad-tibira y de Lugalbanda de Uruk; la de forjador (simug), para Mešhe, también de Uruk; la de batanero $\left({ }^{1 u_{2}} a_{z} l_{a g}\right.$ ), para Susuda de Kiš y Zizi de Mari; barquero $\left({ }^{\mathrm{lu}_{2}} \mathrm{ma}_{2}-\mathrm{lah}\right)$, para Mamagal de Kiš; curtidor ( $\left.{ }^{\mathrm{lu}_{2}} \mathrm{ašgab}\right)$, para Bazi de Mari; sacerdote (gudu 4 ), para Limer de Mari; y cincelador (zadim), para Naniya de Kiš. Todos estos son monarcas presargónicos y ninguno de ellos está documentado en el período Dinástico temprano. Dumuzi, el pastor

37 Ver, por ejemplo, Komoróczy (1973); Beaulieu (2007); Lang (2013); Lanfranchi (2013) y Dalley (2013). 
de Bad-tibira, es el quinto rey antediluviano y su nombre está precedido por el determinativo divino, lo que indica que se trataría de un dios. Lo mismo ocurre con Bazi, el sexagésimo noveno de la lista. ${ }^{38}$ Lugal-banda de Uruk es un personaje literario que en la versión en babilónico estándar de Gilgameš aparece como el progenitor del héroe junto con la diosa Ninsumuna. De los treinta y seis reyes que se mencionan con filiación paterna, el primero es Mašda de Kiš, hijo de Atab, quien lo precedió en el trono. Este dato ubica el surgimiento de la monarquía hereditaria en Kiš, desde la primera vez que recibió la realeza. ${ }^{39}$

Nueve de los reyes de la Lista Real Sumeria cuentan con breves notas biográficas. En orden de aparición ellos son Etana de Kiš, "el pastor que ascendió al cielo y consolidó todas las tierras extranjeras" (1l. 64-67); Enmebaragesi de Kiš, "quien hizo que la tierra de Elam se rindiera" (1l. 83-85); Meškiaĝ, el poderoso, ${ }^{40}$ el primer rey de Eana/Uruk, "hijo del dios Utu que fue señor (en) y rey (lugal)... entró al mar y desapareció" (1l. 96-101); su hijo Enmerkar, "quien construyó la ciudad de Uruk" (11. 102-104); Dumuzi, pescador de Uruk, "cuya ciudad era Kuara... y que capturó solo a Enmebaragesi” (1l. 109-111B); Gilgameš de Uruk, "cuyo padre era un fantasma, ... señor de Kulaba" (1l.112-114); Kug-Bau de Kiš, la tabernera que fortificó cimientos de Kiš" (1l. 224-226); Sargón de Agade, "cuyo padre era un jardinero, el copero de Ur-Zababa, ..., quien construyó Agade” (1l. 266-270); y, por último, Ur-Ninurta de Isin, hijo del dios Iškur, al que se le agrega una expresión de deseo más que una nota biográfica, i.e., "ojalá que tenga años de abundancia, un buen reinado y una vida agradable" (ln. 365). Un breve recorrido por algunos de estos personajes ayuda a dilucidar el lugar que ocupaban en la tradición mesopotámica. Etana es el personaje de un mito que se conoce por manuscritos a partir del período Paleobabilónico (KinnierWilson, 1985). Igual de legendarios son Enmebargesi de Kiš y Gilgameš de Uruk. ${ }^{41}$ Meškiaĝ, es hijo del sol, y su propio descendiente, Enmerkar, es el protagonista de dos textos literarios. ${ }^{42} \mathrm{El}$ caso de Kug-Bau es sorprendente, porque es la única mujer de la lista y su título es "rey" (lugal) y es, además, la única representante de la III dinastía de Kiš (Edzard, 1980-1983: 299). Luego de sus 100 años de reinado, la realeza pasa a la ciudad de Akšak en donde reinan 6 reyes durante 99 años, para luego volver a Kiš donde el hijo de KugBau, Puzur-Suen, hereda el trono de su madre y da inicio a la cuarta dinastía

38 Si bien en la llamada Ballade des héros du temps jadis, los nombres de Bazi y Zizi aparecen con el determinativo de nombre de persona (Cohen, 2012: 139), en un texto literario recientemente publicado, Bazi (escrito con determinativo divino) es un dios hijo de Enki (George, 2009: 6-15).

39 Nótese que la primera vez que Kiš recibió la realeza se dan las siguientes sucesiones hereditarias, donde el poder pasa: 1) de Atab a su hijo Mašda, y de Mašda a su hijo Arwium (ll. 60-62); 2) de Etana a su hijo Balih (In. 69); 3) de En-men-nuna a su hijo MelemKiš y a su hijo Barsal-nuna, de Barsal-nuna a su hijo Zamug y de Zamug a su hijo Tizqar (ll. 72-78); y 4) de Enmebaragesi a su hijo Aka (In. 88).

40 Marchesi (2010: 240 y n. 47).

41 Ver la discusión sobre Enmebaragesi, Gilgameš y Aka en Michalowski (2003).

42 Enmerkar y Enšuhkešdana (Berlin, 1979) y Enmerkar y el Señor de Aratta (Mittermayer, 2009). 
de Kiš. Completan el grupo el rey Sargón de Agade (2334-2279) y Ur-Ninurta de Isin (1923-1896), dos reyes históricos. Del primero se señala su ascenso de hijo de jardinero, a copero del rey de Kiš, hasta convertirse en fundador de una dinastía. Al segundo se lo presenta como hijo de un dios. Claramente, en esta serie de ejemplos, lo mítico se entreteje con lo histórico de forma habitual.

En la Babiloniaca, mitos y leyendas exceden el terreno de la alusión para tomar vuelo narrativo. El Libro I de Beroso ofrece una versión de la creación del universo basada en el Enūma elišs, con una descripción de seres primigenios que sigue de manera laxa e imaginativa a la fuente original, producto quizás de corrupciones posteriores a Beroso. Esta especie de bestiario incluye: 1. hombres con dos alas; 2 . hombres con dos alas y dos rostros; 3. algunos de estos tenían un cuerpo con dos cabezas y dos órganos sexuales, uno masculino y otro femenino; ${ }^{43} 4$. hombres con patas y cuernos de cabra; 5 . otros con vasos de caballo; 6. otros, mitad hombre y mitad caballo, como los hipocentauros; 7. toros con cabezas humanas; 8 . perros con cuatro cuerpos y colas de pez en el cuarto trasero; 9. caballos con cabezas de perro; 10. hombres y otras criaturas con cabezas y cuerpos de caballo; y 11. hombres con cola de pez. A esto se le agregan peces, serpientes, reptiles, creaturas sorprendentes con la apariencia de diferentes animales combinados. Estos seres son una distorsión de las también 11 criaturas de Ti'āmat en el Enūma eliš: 1. serpientes míticas (mušmahh̆ū); 2. dragones furiosos (ušumgallū nadrūtu); 3. víboras (bašmūu); 4. dragones (mušhuššu ); 5. hombres velludos (lahmmū); 6. demonios climáticos (ugallü); 7. hombres-leones (urdimmū ); 8. hombres-escorpiones (girtablì $\bar{u}) ; 9$. demonios agresivos (ümū dabrūtu); 10. hombres-pez (kulīlū), y 11. hombresbisón (kusarikkū). Beroso describe luego el combate entre Bēl (Marduk) y Omorka (Ti'āmat), y la creación del universo y de los hombres.

En el Libro II, después de enumerar a los reyes antediluvianos, se incluye una descripción de la historia del Diluvio. Comienza desde que Kronos/ Enki se le aparece a Xisouthros en sueños y le advierte sobre la inminente llegada del Diluvio que destruirá a la humanidad. Le ordena enterrar todas las tablillas en la ciudad de Sippar. ${ }^{44}$ Le ordena construir un arca para salvar a familiares, amigos y animales. Se incluyen detalles conocidos a través de textos cuneiformes, tales como la excusa que Xisouthros debe darle a la gente de su ciudad, las medidas de la nave y el episodio de las aves que Xisouthros suelta para ver si las aguas habían descendido. Cuando desembarca con su esposa, su hija y el timonero, ofrece sacrificios a los dioses. Luego, los cuatro desaparecen para no volver a ser vistos. Se fueron a vivir a la morada de los

43 Estas criaturas tienen rasgos reminiscentes de los fantásticos seres que eran dos humanos unidos en un solo cuerpo, con una cabeza, pero dos rostros opuestos, cuatro piernas, cuatro brazos y con órganos femeninos y masculinos a los que Aristófanes hace referencia durante su participación en El Simposio de Platón (ver Plato, Great Dialogues, p. 91). Este mito de Aristófanes, a su vez, podría ser una "radical revision of the "battles of Titans, Giants, and centaurs, the fictions of men of old'..." (Hunter, 2004: 62). Estos seres, que no aparecen en Enūma eliš, podrían provenir del trasfondo helenístico de Beroso o de Polihistor o de otro de los transmisores de la Babiloniaca.

44 Se supone que son las tablillas que contienen todos los conocimientos transmitidos por los sabios hombres-pez (Verbrugghe y Wickersham, 2000: 49). 
dioses, en clara alusión a la inmortalidad que Uta-napištim y su esposa obtienen en la tablilla XI de Gilgameš. ${ }^{45}$ El resto de los sobrevivientes vuelven a Sippar para rescatar la sabiduría antediluviana. Se reiniciaba así el ciclo de la civilización. Luego de narrar el Diluvio, Beroso parece haber retomado la enumeración de reyes. La lista se expande, en algunos casos específicos, con detalles biográficos y anecdóticos.

\section{Conclusión}

La idea de historia y la escritura de la historia han experimentado numerosas mutaciones desde las indagaciones de Heródoto en el siglo V a.C. hasta la actualidad. Con sus historíai, Heródoto iniciaba una nueva forma de escribir sobre el pasado. Tucídides, distanciándose de su insigne antecesor, puso el énfasis sobre la veracidad de los hechos narrados y sobre el método con el que debía encararse el estudio del pasado. Desde ese entonces y ya entrado el siglo XX, la historia política y las hazañas de los grandes hombres ocupaban un lugar destacado en las agendas de los historiadores. Las tensiones entre lo mítico y lo histórico eran una constante en las discusiones historiográficas de esas épocas. A partir del siglo XX comenzó a predominar la historia económica y social, se afianzó la historia cultural, se revaloró la historia oral y surgieron, por ejemplo, la historia desde abajo, los estudios subalternos y la historia de las minorías. Representantes del postmodernismo discutieron y resignificaron el viejo problema de las tensiones entre historia y literatura y verdad y ficción. También se vaticinó el fin de la historia. La aplicación de métodos cuantitativos permite ahora encontrar, serializar y entrecruzar información voluminosa en fracción de segundos. Los antiguos no pueden competir con las sofisticadas bases de datos de los historiadores modernos. En retrospectiva, examinar la idea de historia antes de Heródoto es como continuar leyendo el pasado con las lentes del siglo XIX. También lo es esperar encontrar en textos como la Lista Real Sumeria y la Babiloniaca un repositorio de hechos históricos objetivos.

Este trabajo plantea la alternativa de tratar de comprender cómo se representaba el pasado en dos textos de la Mesopotamia antigua. La Lista Real Sumeria y la Babiloniaca son dos obras excepcionales arraigadas en una misma tradición, pero originadas en contextos históricos y socio-culturales absolutamente distintos. Una fue compuesta durante el apogeo y la otra durante el irreversible ocaso de la civilización cuneiforme. Tienen la peculiaridad de ofrecer visiones abarcadoras del pasado donde la larga duración surge de la concatenación de acontecimientos puntuales y de la combinación de recortes arbitrarios del pasado. La Lista Real Sumeria fue modelada en base a las tempranas listas cuneiformes que compilaban desde nombres de dioses hasta términos jurídicos, en algunos casos, con el agregado de anotaciones breves. La Babiloniaca, en cambio, seguía el estilo narrativo de las composiciones griegas. Ambas recrean un pasado poblado de personajes ficticios y reales, a la vez que ofrecen datos inverosímiles avalados por el riguroso cómputo de

45 Para las fuentes de las que disponía Beroso ver, e.g., Komoróczy (1973); Dalley (2013); Lang (2013). 
años para crear la impresión de veracidad. Los dos documentos, a su manera, le otorgan un lugar central a la realeza, a la idea de la más remota antigüedad de la cultura cuneiforme y a la ilusión de una continuidad formada en base a interrupciones persistentes que garantizan la permanencia en el tiempo y en la memoria. 


\section{Q Bibliografía}

\section{Fuentes}

» Aristóteles. Poetics (trad. G. Else, 1970). Ann Arbor: University of Michigan Press.

»Cicerón. The Laws (trad. N. Rudd, 1998). Oxford: Oxford University Press.

»Luciano. How to Write History (trad. K. Kilburn, 1959). Lucian VI (LCL 430). Cambridge, MA.: Harvard University Press.

»Platón. Great Dialogues of Plato. (trad. W. H. D. Rouse, 1999). Nueva York: Signet Classics.

»Plutarco. De Herodoti malignitate (trad. L. Pearson, 1965). Plutarch's Moralia XI (LCL 499). Cambridge, MA.: Harvard University Press.

\section{Estudios}

»Beaulieu, P.-A. (2007). Berossus on Late Babylonian History, en: Gong, Y. (ed.), A Collection of Papers on Ancient Civilizations of Western Asia, Asia Minor and North Africa. Beijing: Oriental Studies Special Issue 2006, 116-134.

»Berlin, A. (1979). Enmerkar and Esuhkešdanna: a Sumerian Narrative Poem. Filadelfia: University Museum.

"Boiy, T. (2004). Late Achaemenid and Hellenistic Babylon (OLA 136). Lovaina: Peeters.

» Bossuet, J. B. (1844). Discours sur l'histoire universelle. París: Chez Lefevre.

» Braudel, F. (1949). La Méditerranée et le monde méditerranéen à l'époque de Philippe II. París: Colin.

» Burke, P. (1993). History and Social Theory. Cambridge: Polity Press.

»Burke, P. (ed.). (1995). New Perspectives on Historical Writing. Pensilvania: Pennsylvania State University.

»Burstein, S. (1978). The Babyloniaca of Berossus (SANE 1/5). Malibu: Undena Publications.

»Cohen, Y. (2012). Where Is Bazi? Where Is Zizi?, en: Iraq 74: 137-152.

"Dalley, S. (2013). First Millennium BC Variation in Gilgamesh, Atrahasis, the Flood Story and the Epic of Creation: What was Available to Berossos?, en: Haubold, J. et al. (eds.), The World of Berossos. Proceedings of the 4 th International Colloquium on "The Ancient Near East between Classical and Ancient Oriental Traditions", Hatfield College, Durham 7th-gth July 2010. Wiesbaden: Harrassowitz, 165-176.

»De Breucker, G. (2011). Berossos between Tradition and Innovation, en: Radner, K. y Robson, E. (eds.), The Oxford Handbook of Cuneiform Culture. Oxford: Oxford University Press, 637-657. 
»De Breucker, G. (2013). Berossos: His Life and His Work, en: Haubold, J. et al. (eds.), The World of Berossos. Proceedings of the 4th International Colloquium on "The Ancient Near East between Classical and Ancient Oriental Traditions", Hatfield College, Durham 7th-gth July 2010. Wiesbaden: Harrassowitz, 15-28.

»Dillery, J. (2015). Clio’s Other Sons. Berossus \& Manetho. Ann Arbor: The University of Michigan.

"Dobb, M. (1946). Studies in the Development of Capitalism. Londres: Routledge.

" Edzard, D. O. (1980-1983). Ku(g)-Baba, en: Reallexikon der Assyriologie 6: 299.

"Foley, A. (2016). Valla's Herodotean Labors: Towards a New View of Herodotus in the Italian Renaissance, en: Priestley, J. y Zali, V. (eds.), Brill's Companion to the Reception of Herodotus in Antiquity and Beyond. Leiden: E. J. Brill, 213-231.

» Foster, B. (1991). On Authorship in Akkadian Literature, en: Annali 51: 17-32.

» Gabba, E. (1981). True History and False History in Classical Antiquity, en: The Journal of Roman Studies 71: 50-62.

» George, A. (2009). Babylonian Literary Texts in the Schøyen Collection (CUSAS 10). Bethesda, Md.: CDL Press.

» Ginzburg, C. (1976). Il formagio e i vermi: il cosmo di un mugnaio del '50o. Turín: Einaudi.

" Green, P. (1990). Alexander to Actium: The Historical Evolution of the Hellenistic Age. Berkeley: University of California Press.

» Hartog, F. (1988). The Mirror of Herodotus. The Representation of the Other in the Writing of History. Berkeley: University of California Press.

»Hartog, F. (2002). The Invention of History: From Homer to Herodotus, en: Wang, Q. y Iggers, G. (eds.), Turning Points in Historiography: A Cross-Cultural Perspective. Rochester, NY: The University of Rochester Press, 19-29.

"Haubold, J. (2013). "The Wisdom of the Chaldeans": Reading Berossos, Babyloniaca Book I, en: Haubold, J. et al. (eds.), The World of Berossos. Proceedings of the 4th International Colloquium on "The Ancient Near East between Classical and Ancient Oriental Traditions", Hatfield College, Durham 7th-9th July 2010. Wiesbaden: Harrassowitz, 31-45.

» Haubold, J. et al. (eds.). (2013). The World of Berossos. Proceedings of the 4th International Colloquium on "The Ancient Near East between Classical and Ancient Oriental Traditions", Hatfield College, Durham 7th-gth July 2010. Wiesbaden: Harrassowitz.

» Hegel, G. W. F. (1942). The Philosophy of History. Ann Arbor: Edwards Brothers.

" Hegel, G. W. F. (1998). Lectures on the Philosophy of World History. Traducción de H. B. Nisbet. Cambridge: Cambridge University Press.

"Hilprecht, H. V. (1906). Mathematical, Metrological and Chronological Tablets from the Temple Library of Nippur (The Babylonian Expedition of the University of Pennsylvania. Series A: Cuneiform Texts. BE XXI). Filadelfia: Department of Archaeology of the University of Pennsylvania.

"Houston, S., Baines, J. y Cooper, J. (2003). Last Writing: Script Obsolescence in Egypt, Mesopotamia, and Mesoamerica, en: Comparative Studies in Society and History 45: 430-479.

» Hunter, R. (2004). Plato's Symposium. Oxford: Oxford University Press. 
» Jacobsen, T. (1973). The Sumerian King List (AS 11). 4ta ed. Chicago: The Oriental Institute.

» Kinnier-Wilson, J. (1985). The Legend of Etana. A New Edition. Warminster: Aris and Phillips.

» Komoróczy, G. (1973). Berosos and the Mesopotamian Literature, en: Acta Antiqua XXI: 125-152.

» Kramer, S. (1978 [1956]). La Historia empieza en Sumer. Barcelona: Ayma S.A. Editora.

» Kuhrt, A. (1987). Berossus' Babyloniaka and Seleucid Rule in Babylonia, en: Kuhrt, A. y Sherwin-White, S. (eds.), Hellenism in the East. The Interaction of Greek and non-Greek Civilization. Londres: Duckworth, 32-56.

»Lanfranchi, G. (2013). Babyloniaca, Book 3: Assyrians, Babylonians and Persians, en: Haubold, J. et al. (eds.), The World of Berossos. Proceedings of the 4th International Colloquium on "The Ancient Near East between Classical and Ancient Oriental Traditions”, Hatfield College, Durham 7th-gth July 2010. Wiesbaden: Harrassowitz, 61-74.

》Lang, M. (2013). Book Two: Mesopotamian Early History and the Flood Story, en: Haubold, J. et al. (eds.), The World of Berossos. Proceedings of the 4th International Colloquium on "The Ancient Near East between Classical and Ancient Oriental Traditions", Hatfield College, Durham 7th-gth July 2010. Wiesbaden: Harrassowitz, 47-60.

»Langdon, S. H. (1923). Historical Inscriptions, Containing Principally the Chronological Prism, W-B. 444 (Oxford Edition of Cuneiform Texts II). Oxford: Oxford University Press.

»Lehmann-Haupt, C. F. (1938). Berossos, en: Reallexikon der Assyriologie 2: 1-17.

»Lenormant, F. (1869). Manuel d'histoire ancienne de l'Orient jusqu'aux guerres médiques. Tome premier. Temps primitifs. Israélites. Égyptiens. París: Maisonneuve et Ce.

»Marchesi, G. (2010). The Sumerian King List and the Early History of Mesopotamia, en: Biga, M. G. y Liverani, M. (eds.), Ana turri gimilli. Studi dedicati al Padre Werner R. Mayer, S. J. da amici e allievi. Roma: Università degli Studi di Roma “La Sapienza”, 231-248.

"Marincola, J. (2016). History without Malice: Plutarch Rewrites the Battle of Plataea, en: Priestley, J. y Zali, V. (eds.), Brill's Companion to the Reception of Herodotus in Antiquity and Beyond. Leiden: E. J. Brill, 101-119.

» Michalowski, P. (1983). History as Charter. Some Observations on the Sumerian King List, en: Journal of the American Oriental Society 103: 237-248.

»Michalowski, P. (2003). A Man Called Enmebaragesi, en: Sallaberger, W., Volk, K. y Zgoll, A. (eds.), Literatur, Politik und Recht in Mesopotamien. Festschrift für Claus Wilcke. Wiesbaden: Harrassowitz, 195-207.

»Mittermayer, C. (2009). Enmerkara und der Herr von Arata: ein ungleicher Wettstreit (OBO 239). Friburgo: Academic Press.

" Momigliano, A. (1957). Erodoto e la storiografia moderna: alcuni problema presentati ad un convegno di humanistici, en: Aevum 31: 74-84.

"Momigliano, A. (1958). The Place of Herodotus in the History of Historiography, en: History 43/147: 1-13. 
» Morley, N. (2016). The Anti-Thucydides: Herodotus and the Development of Modern Historiography, en: Priestley, J. y Zali, V. (eds.), Brill's Companion to the Reception of Herodotus in Antiquity and Beyond. Leiden: E. J. Brill, 143-166.

»Priestley, J. y Zali, V. (eds.). (2016). Brill's Companion to the Reception of Herodotus in Antiquity and Beyond. Leiden: E. J. Brill.

» Ranke, L. von. (1885). Geschichten der romanischen und germanischen Völker von 1494 bis 1514. Leipzig: Verlag von Duncker \& Humblot.

"Schnabel, P. (1923). Berossos und die babylonisch-hellenistiche Literatur. Leipzig: Verlag und Druck von G.G. Teubner.

»Schironi, F. (2013). The Early Reception of Berossos, en: Haubold, J. et al. (eds.), The World of Berossos. Proceedings of the 4 th International Colloquium on "The Ancient Near East between Classical and Ancient Oriental Traditions", Hatfield College, Durham 7th-gth July 2010. Wiesbaden: Harrassowitz, 235-254.

»Steinkeller, P. (2003). An Ur III Manuscript of the Sumerian King List, en: Sallaberger, W., Volk, K. y Zgoll, A. (eds.), Literatur, Politik und Recht in Mesopotamien. Festschrift für Claus Wilcke. Wiesbaden: Harrassowitz, 267-292.

» Stone, L. (1979). The Revival of Narrative History: Reflections on a New Old History, en: Past and Present 85: 3-24.

»Van der Spek, R. (2000). The šatammus of Esagila in the Seleucid and Arsacid Periods, en: Marzahn, J. y Neumann, H. (eds.), Assyriologica et Semitica. Festschrift für Joachim Oelsner anläßlich seines 65. Geburtstages am 18. Februar 1997 (AOAT 252). Münster: Ugarit Verlag, 437-446.

» van Dijk, J. (1962). Die Inschriftenfunde: II Die tontafeln aus dem res-Heiligtum, en: Vorläufiger Bericht über die von dem Deutschen Archäologischen Institut und der Deutschen Orient-Gesellschaft aus Mitteln der Deutschen Forschungsgemeinschaft unternommenen Ausgrabungen in Uruk-Warka (1959-60) (UVB 189). Berlín: Heinrich J. Lenzen, 39-62 y II. 20, 27-28.

»Verbrugghe, G. P. y Wickersham, J. M. (2000). Berossos and Manetho. Introduced and Translated. Native Traditions in Ancient Mesopotamia and Egypt. Ann Arbor: The University of Michigan.

»Vincente, C.-A. (1995). The Tall Leilān Recension of the Sumerian King List, en: Zeitschrift für Assyriologie und Vorderasiatische Archäologie 85: 234-270.

》White, H. (1973). Metahistory. The Historical Imagination in the Nineteenth-Century. Baltimore: The Johns Hopkins University Press.

»Wilcke, C. (2001). Gestaltetes Altertum in antiker Gegenwart: Königlisten und Historiographie des älteren Mesopotamien, en: Kuhn, D. y Stahl, H. (eds.), Die Gegenwart des Altertums. Formen und Funktionen des Altertumsbezugs in den Hochkulturen der Alten Welt. Heidelberg: Forum, 93-116. 
